University for Business and Technology in Kosovo

UBT Knowledge Center

UBT International Conference

2016 UBT International Conference

Oct 28th, 9:00 AM - Oct 30th, 5:00 PM

\title{
Fuzzy logic controlofgantry crane system
}

\author{
Betim Shabani \\ University for Business and Technology, betim.shabani@hotmail.com
}

Follow this and additional works at: https://knowledgecenter.ubt-uni.net/conference

Part of the Engineering Commons, and the Physical Sciences and Mathematics Commons

\section{Recommended Citation}

Shabani, Betim, "Fuzzy logic controlofgantry crane system" (2016). UBT International Conference. 46.

https://knowledgecenter.ubt-uni.net/conference/2016/all-events/46

This Event is brought to you for free and open access by the Publication and Journals at UBT Knowledge Center. It has been accepted for inclusion in UBT International Conference by an authorized administrator of UBT Knowledge Center. For more information, please contact knowledge.center@ubt-uni.net. 


\title{
Fuzzy logic controlofgantry crane system
}

\author{
Betim Shabani \\ UBT - Higher Education Institution, Lagjja Kalabria, 10000 p.n., \\ Prishtine, Kosovo \\ betim.shabani@hotmail.com
}

\begin{abstract}
The use of gantry crane systems for transporting payload is very common in industrial application. However, moving the payload using the crane is not an easy task especially when strict specifications on the swing angle and on the transfer time need to be satisfied. To overcome this problem, an intelligent gantry crane system had been introduced. Fuzzy logic controllers were adopted, designed and implemented for controlling payload position as well as the swing angle of the gantry crane. Fuzzy logic defines rules that determine the behavior of the system using word descriptions instead of mathematical equations also fuzzy logic control algorithms can be used to solve problems that are difficult to address with traditional control techniques. Fuzzy control strategy is proposed to control the stability of crane work.
\end{abstract}

Keyword: Fuzzy logic controllers, Gantry crane system

\section{Introduction}

The development of an active suspension system for high performance cranes that aims to reduce the vibrations in the base of the crane's frame. The oscillations are caused mainly by disturbances that come from the contact between the rollers parts of the suspensions with the alignment guides fixed to the building structure during the crane movement. These guides, although modern processes of manufacture and installation, present inherently small misaligns that are caused normally by disturbances in the installation processes. The movements caused for the semis alignments, mainly for the high speed cranes of high building (skyscrapers), can compromise the requirements of security and comfort. Consequently, high technology companies are spending resources in the development of modern systems, as active control, to improve the performance of the crane's suspensions without increasing its size and weight, as occurs with the traditional passive systems.

This situation can be proven by the elevated number of patents since the middle of the last decade. In this work it is aimed to reduce the vibration of the crane using fuzzy logic algorithm in order to make an accurate masses translation. [1] 
Book of Proceedings

International Conference on Mechatronics, Sciences in Energy Efficiency Engineering,

System Engineering and Robotics

\section{Mathematical modeling of gantry crane}

A schematic diagram of a gantry crane model is shown in Fig 1.Generally the configuration of this model is specified by the horizontal position of trolley $x$, the length of the hoisting cable $l$, and the sway angle theta $\theta$. [2]A number of assumptions are made in order to simplify the system:

- The trolley and the payload move or oscillate in x plane.

- The tension force that will cause the hoisting cable to elongate is neglected.

- Both the trolley and the payload are considered as point masses.

- The friction between the trolley and the rail is neglected.

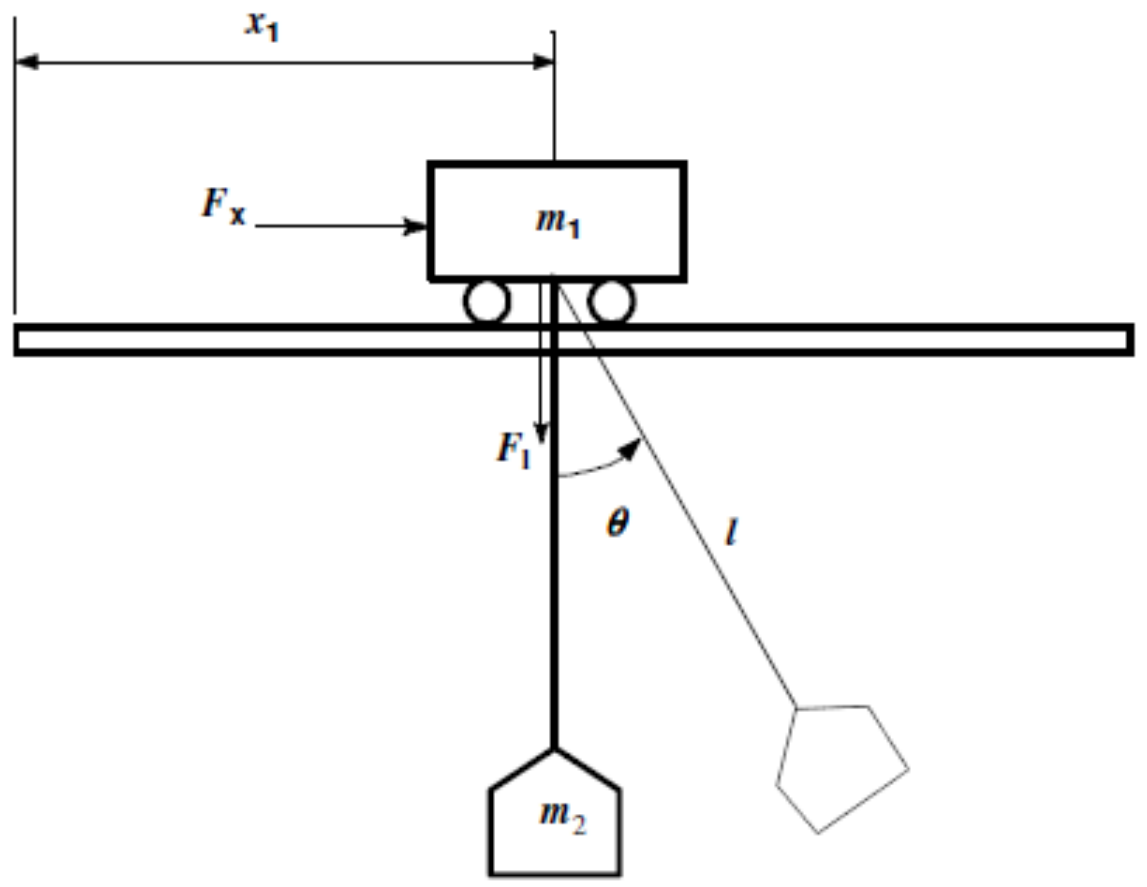

Fig. 1. Schematic diagram of a gantry crane model

The equations of motion for a linearized model of a gantry crane are represented as follows:

$F_{x}=\left(m_{1}+m_{2}\right) \ddot{x}+m_{2} l \ddot{\theta}$

$$
\begin{gathered}
l \ddot{\theta}+\ddot{x}+g \theta=0 \\
F_{t}=m_{2} \ddot{x} \theta-m_{2} g
\end{gathered}
$$




\section{Dynamic model of gantry crane}

The mathematical model of the gantry crane was developed and its parameters are identified. The developed gantry crane model is used to design controller, and to make simulation. The developed model of the crane is:

$$
\begin{gathered}
\frac{X_{(S)}}{U_{(S)}}=\frac{1.28}{s\left(0.002689 s^{2}+0.2529 s+1.314\right)} \\
\frac{\theta_{(S)}}{X_{(S)}}=\frac{-s^{2}}{3 s^{2}+9.81}
\end{gathered}
$$

where $\mathrm{U}(\mathrm{s}), \mathrm{X}(\mathrm{s})$ and $\theta(\mathrm{s})$ are input power, trolley displacement and load swing angle respectively.

\section{Proposed controller}

The structure of the proposed controller for the gantry crane system is shown in Figure 2. The proposed controller consists of fuzzy logic controllers for both position and anti-swing control respectively. The objective of the proposed fuzzy logic controllers is to control the payload position X(s) so that it moves to the desired position $\operatorname{Xref}(\mathrm{s})$ as fast as possible without excessive swing angle of the payload $\theta(\mathrm{s})$. [3]

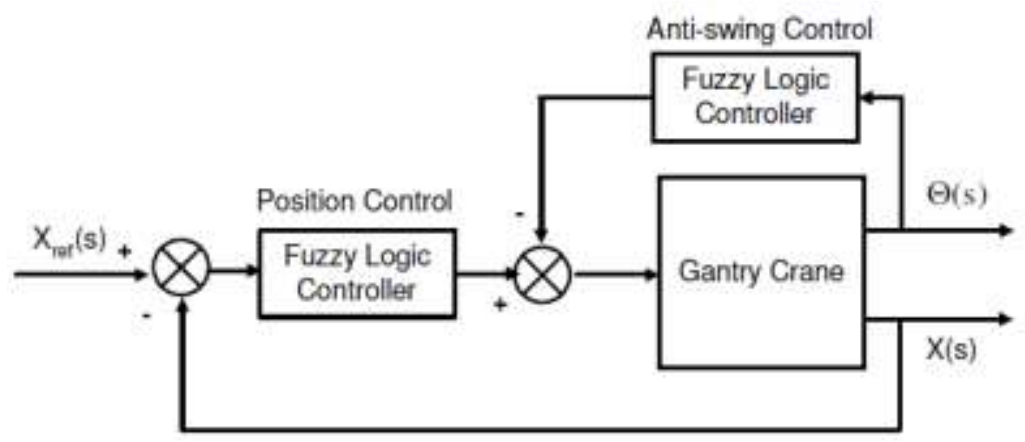

Fig. 2. Proposed fuzzy-based intelligent gantry crane system 
Book of Proceedings

International Conference on Mechatronics, Sciences in Energy Efficiency Engineering,

System Engineering and Robotics

For our system we have this structure of the model in Simulink:

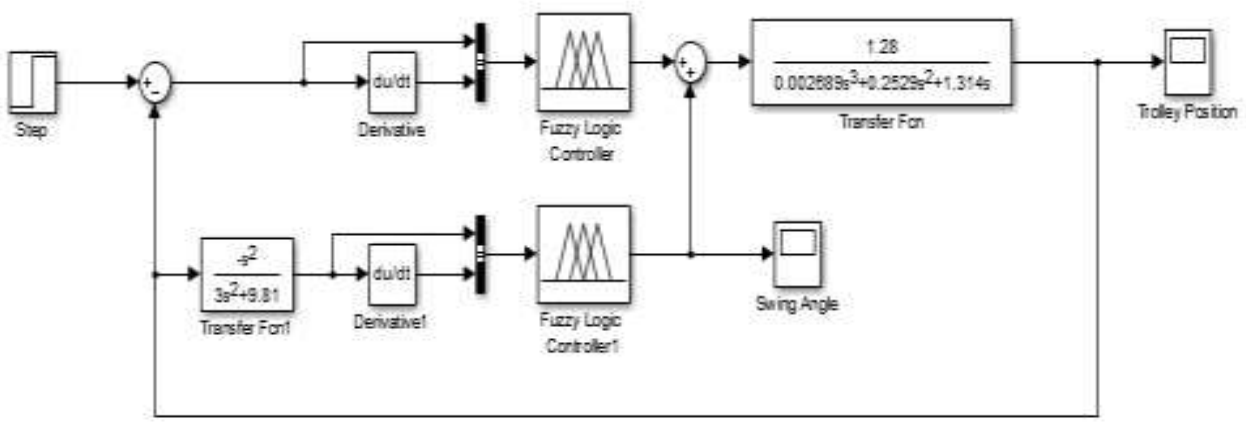

Fig. 3. Simulink diagram of the proposed system

\section{Design of Fuzzy Logic Controller}

The main design process of the fuzzy logic controller consists of the development of input and output of the membership functions, fuzzy rule base and defuzzification method. In the position control, error and error rate of position are taken into consideration as inputs. On the other hand, swing angle and swing angle rate are used as inputs for anti-swing control. Meanwhile, the voltage is taken as an output. [3]

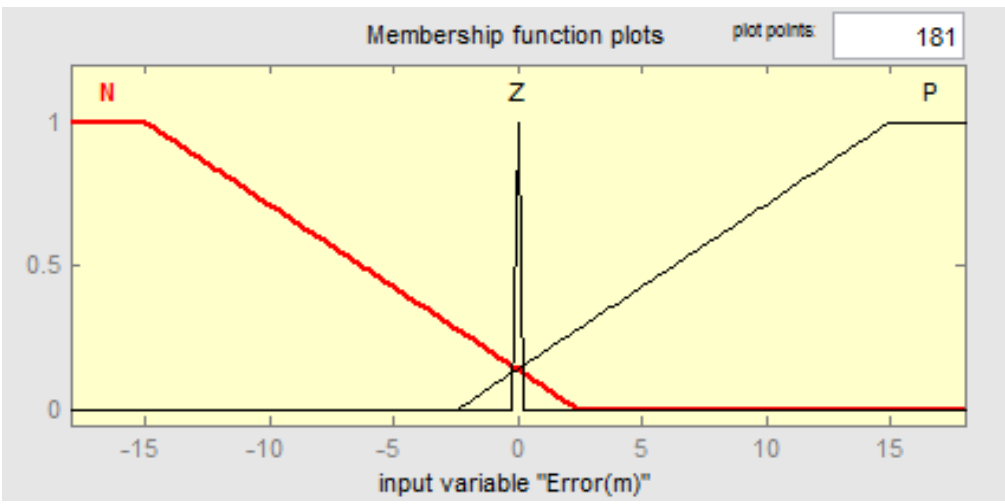



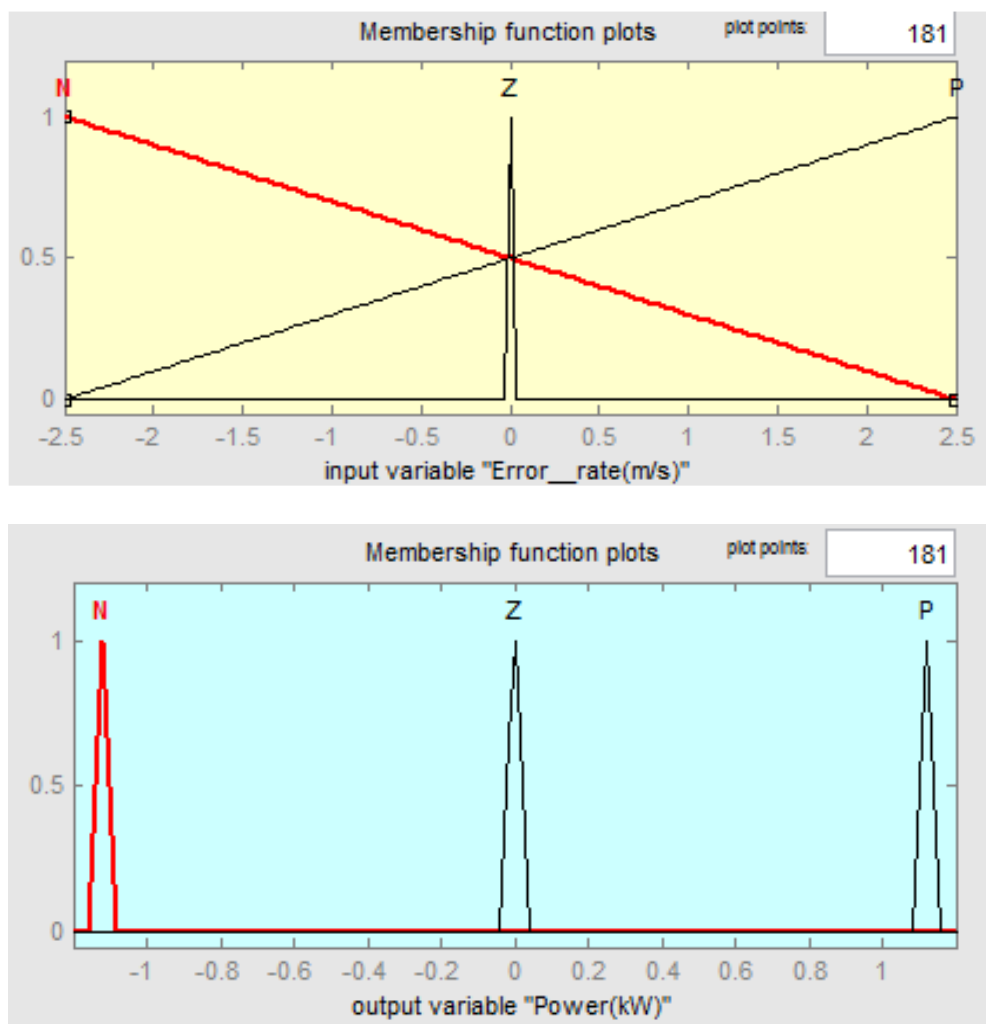

Fig. 4. Membership function for Trolley Position

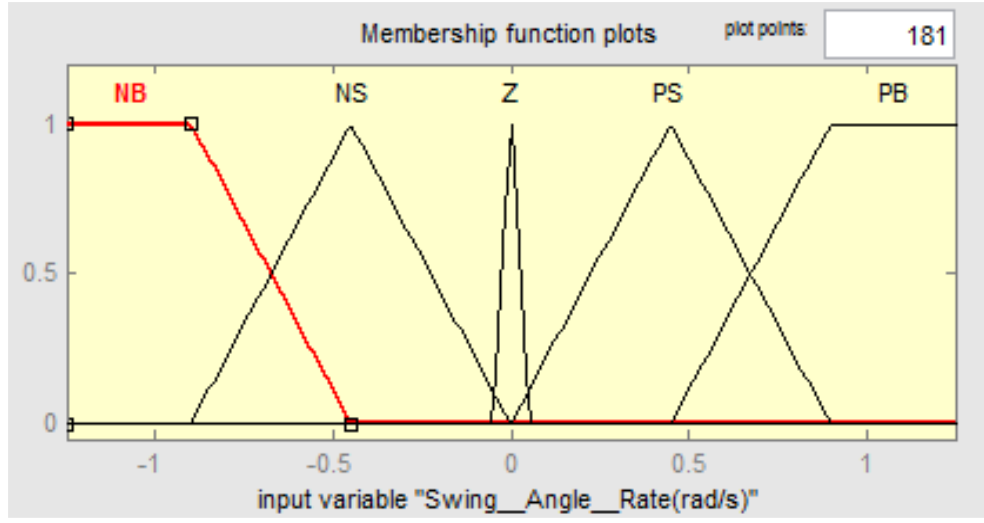


Book of Proceedings

International Conference on Mechatronics, Sciences in Energy Efficiency Engineering,

System Engineering and Robotics
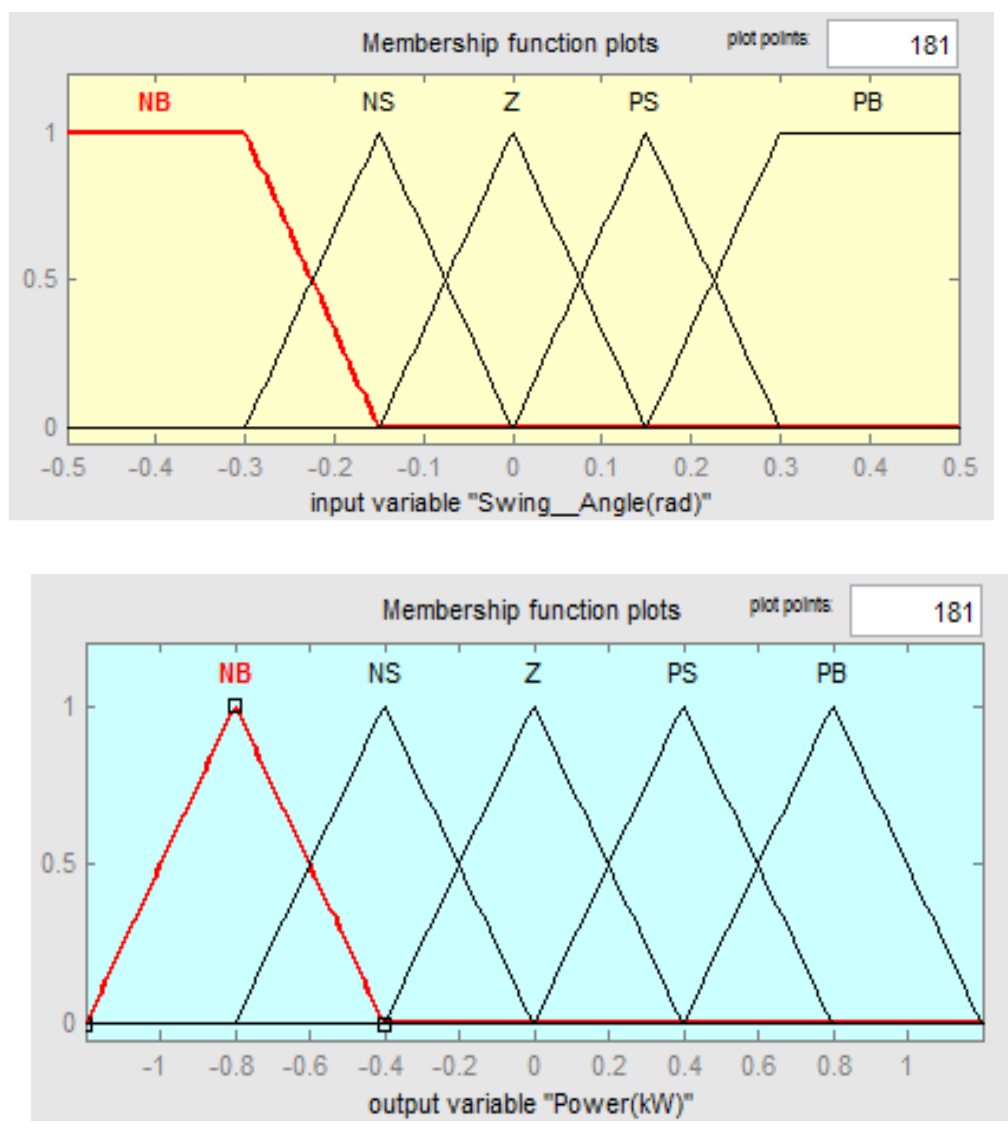

Fig. 5. Membership function for Swing Angle

The rules of fuzzy position and fuzzy anti-swing controls are adopted from experiences. Therefore, error and error rate are used in order to generate the rules. Tables 1 and 2 list the generated linguistic rules for position and anti-swing control respectively.

\begin{tabular}{|l|c|c|c|c|}
\hline \multicolumn{2}{|c|}{ Error Rate } & \multicolumn{3}{|c|}{ Error rate } \\
\cline { 3 - 5 } \multicolumn{2}{|c|}{ Error } & $\mathrm{P}$ & $\mathrm{Z}$ & $\mathrm{N}$ \\
\hline \multirow{3}{*}{ Error } & $\mathrm{P}$ & $\mathrm{P}$ & $\mathrm{P}$ & $\mathrm{P}$ \\
\cline { 2 - 5 } & $\mathrm{Z}$ & $\mathrm{N}$ & $\mathrm{Z}$ & $\mathrm{P}$ \\
\cline { 2 - 5 } & $\mathrm{N}$ & $\mathrm{N}$ & $\mathrm{N}$ & $\mathrm{N}$ \\
\hline
\end{tabular}


Fuzzy logic controlofgantry crane system

Tab.1. Fuzzy rule base of position control

Tab.2. Fuzzy rule base of anti-swing control

As we show, we have two fuzzy logic controllers, one for trolley position and one for swing angle:

FIS Editor: Trolley_Position

吕 $\mid$ 回|x

File Edit View

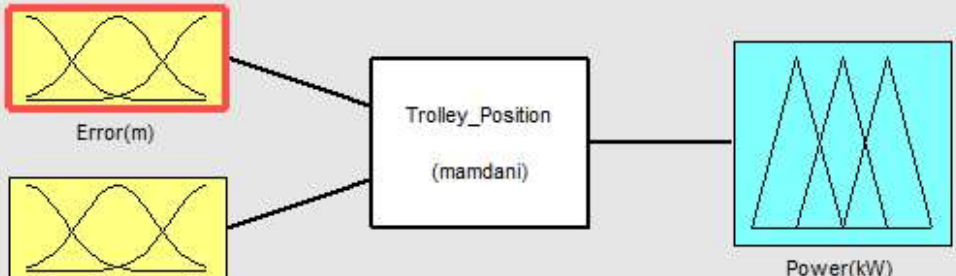

Error_rate(m/s)

FIS Name: $\quad$ Trolley_Position mamdani

And method $\quad$ min Current Variable

Or method

Implication

Aggregation

Defuzzification

Name

Type

Range

Error(m)

input

$\min$

$\max$

$\checkmark$

Help Close

System Trolley_Position": 2 inputs, 1 output, and 9 rules

Fig. 6. FIS Editor for Trolley Position 
Book of Proceedings

International Conference on Mechatronics, Sciences in Energy Efficiency Engineering, System Engineering and Robotics

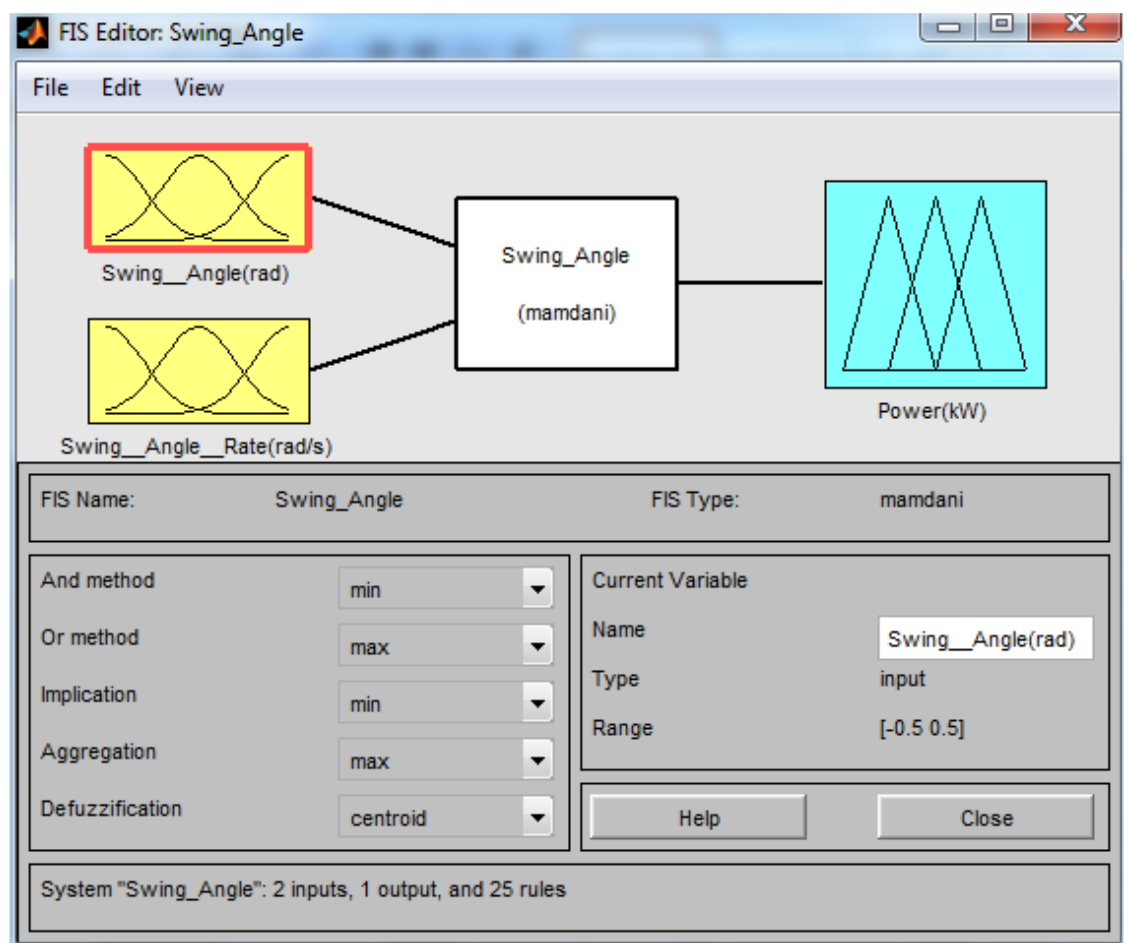

Fig. 7. FIS Editor for Swing angle

\section{Results}

So while we do not have a system of crane which is tested in lab or in practice, as such topic is examined in a system of crane parameters assumed by experience but also by calculation which they are based on the power of the motor. In our case, the motor has the power of $3.7 \mathrm{~kW}$ which is sufficient for moving the crane with these maximal parameters:

- $\quad$ Mass of trolley $=5 \mathrm{kN}$

- $\quad$ Mass of payload $=30 \mathrm{kN}$

- $\quad$ Cable length $=3 \mathrm{~m}$

- $\quad$ Distance $=18 \mathrm{~m}$

Based on the simulation in Matlab software we have gained these results for this case: 


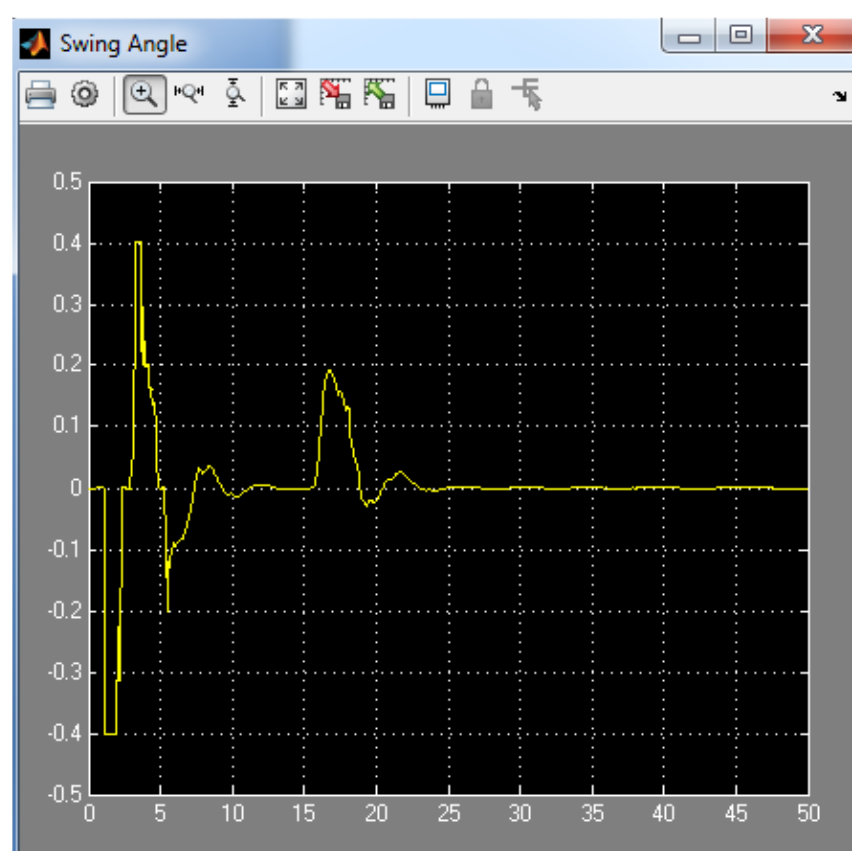

Fig. 7. Diagram time(s) / position (m)

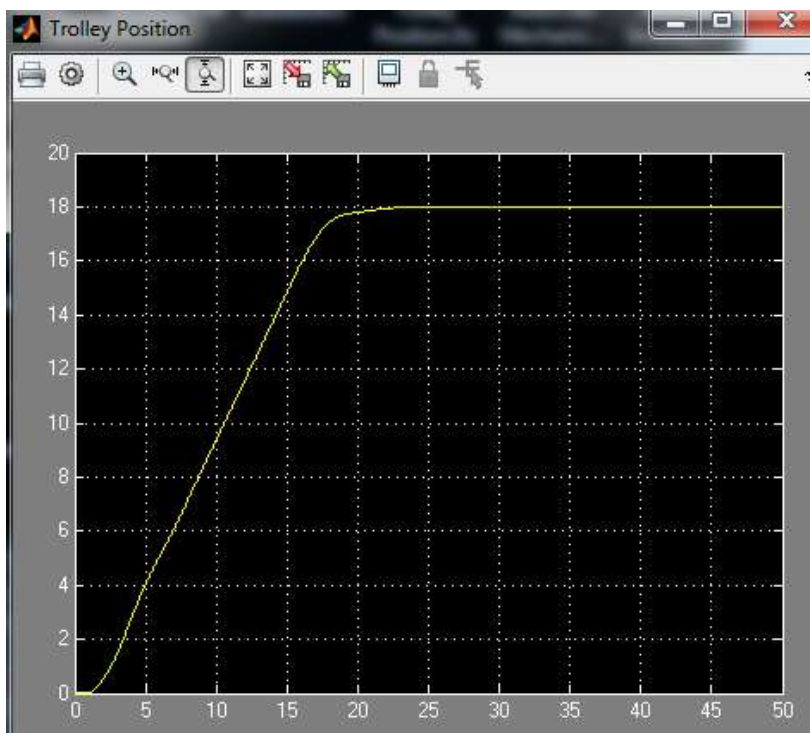

Fig.8. Diagram time(s) / swing angle (rad) 
Book of Proceedings

International Conference on Mechatronics, Sciences in Energy Efficiency Engineering,

System Engineering and Robotics

\section{Different results of simulation}

- Distance: $2 \mathrm{~m}$

- Cable length: $3 \mathrm{~m}$

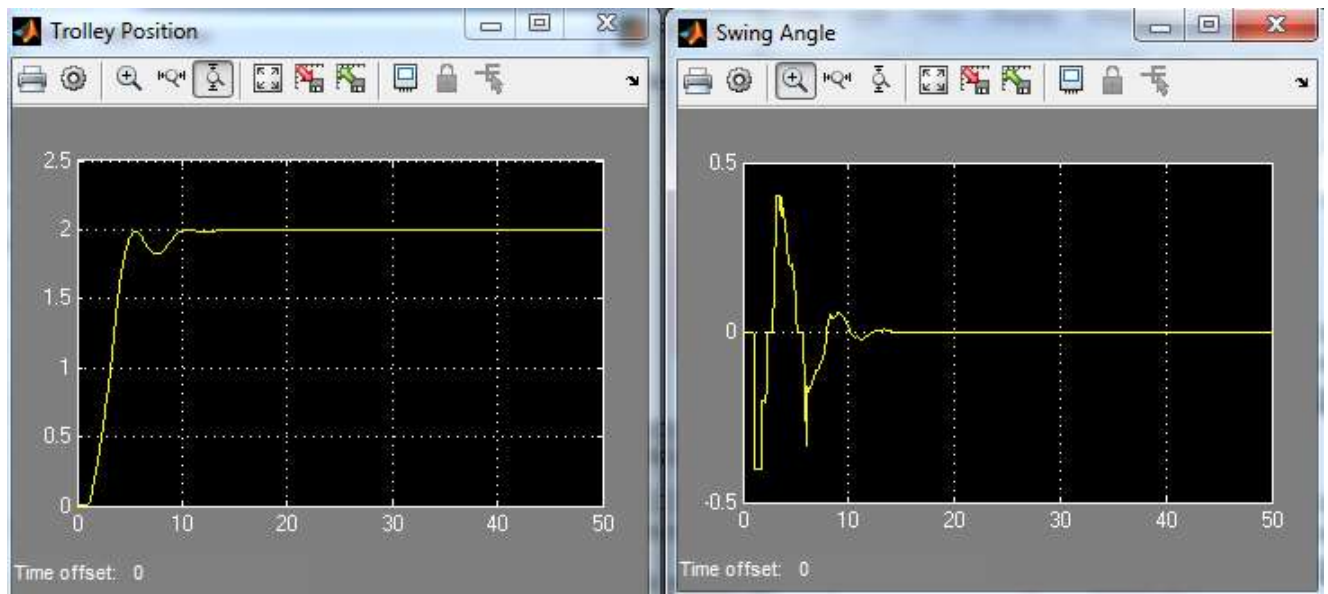

Fig. 9. Diagram time (s) / trolley position (m) and swing angle (rad)

-Distance: $5 \mathrm{~m}$

-Cable length: $1 \mathrm{~m}$

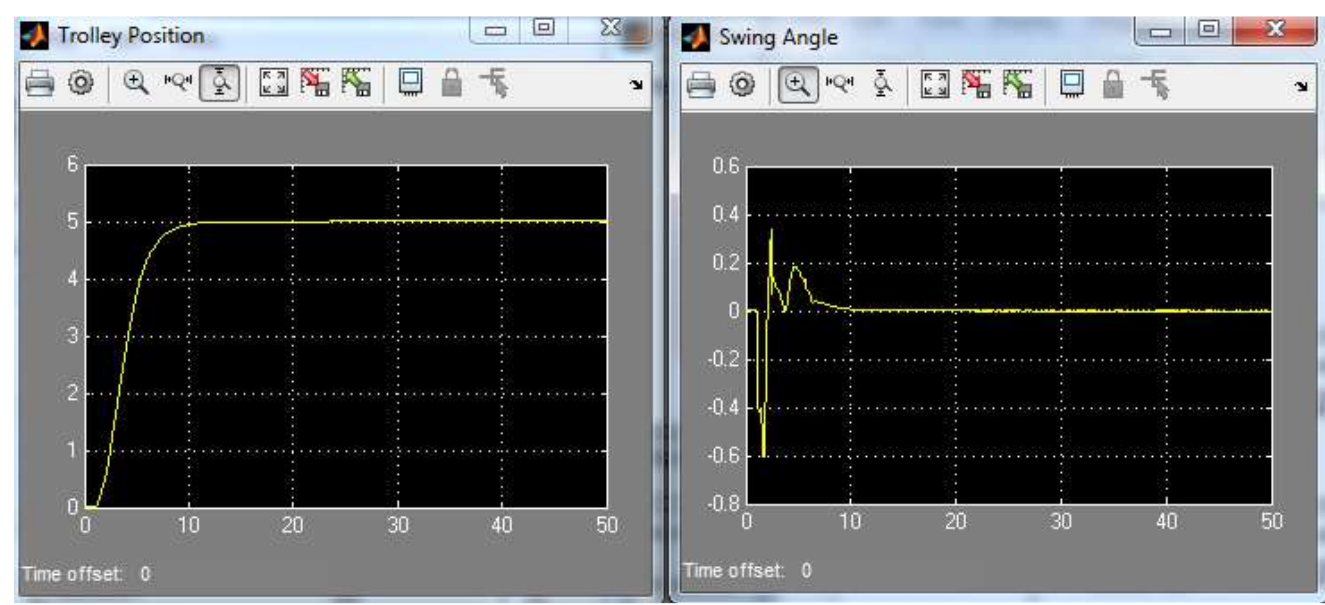

Fig. 10. Diagram time (s) / trolley position (m) and swing angle (rad) 
Fuzzy logic controlofgantry crane system

\section{Conclusion}

Fuzzy logic controllers were adopted and designed for realizing the intelligent gantry crane system. The result shows that the intelligent gantry crane system has a performance and more robust to parameter variation. By using the developed model, the dynamic behavior of the controller has been evaluated using Matlab and Simulink. The performances of the controller are examined in terms of vibration reduction of sway angle and a stable positioning.

\section{References}

1. Iman. A. Zayer, "FUZZY LOGIC CONTROL OF CRANE SYSTEM," The Iraqi Journal For Mechanical And Material Engineering, Vol.11, No.3,,pp. 437-438, 2011.

2. Musa Mailah, Chia Soon Yoong, "DISTURBANCE REJECTION CONTROL APPLIED," 2008.

3. Wahyudi and JamaludinJalani, "Design and Implementation of Fuzzy Logic Controller for an Intelligent Gantry" 